\title{
Erratum: Mental health research in African organisations: Advancing theory and practice
}

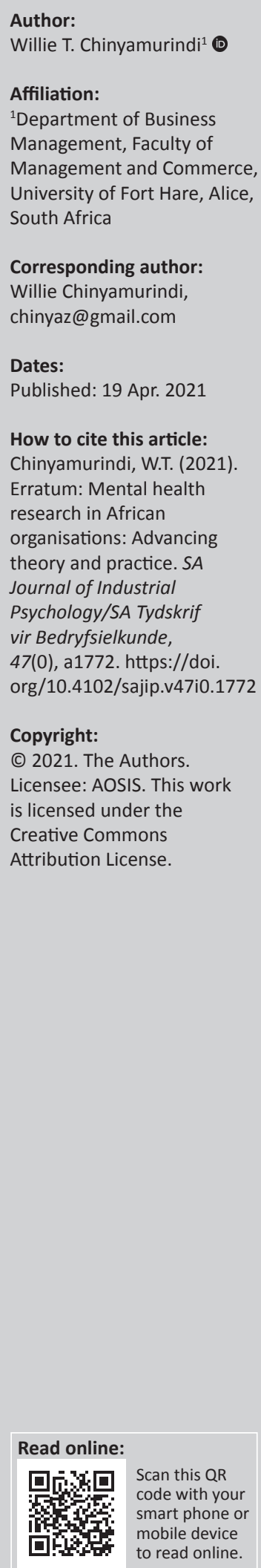

In the version of this article initially published, Chinyamurindi, W.T., (2019). Mental health research in African organisations: Advancing theory and practice. SA Journal of Industrial Psychology/SA Tydskrif vir Bedryfsielkunde, 45 (0), a1727. https://doi.org/10.4102/sajip. v45i0.1727, the article section was given incorrectly. The correct section should be Editorial instead of Original Research.

This correction does not alter the study's findings of significance or overall interpretation of the study's results. The publisher apologises for any inconvenience caused. 